\title{
FOVEAL AND EXTRAFOVEAL INFLUENCES ON THE TOPOGRAPHY OF THE VISUALLY EVOKED, EARLY NEGATIVE POTENTIAL IN MAN $^{1}$
}

\author{
Kenneth A. Kooi, Richard P. Tucker, Jacob Danial and Robert E. Marshall \\ Departments of Psychiatry and Neurology, University of Michigan Medical Center, Ann Arbor, Mich. 48104 (U.S.A.)
}

(Accepted for publication: January 21, 1972)

Anatomically, the retina can be divided into (1) a central area which includes the central fovea and parafovea, and (2) a peripheral region. Polyak (1941) states that in man the visual angle corresponding to the floor of the foveal region is slightly more than $1^{\circ}$, that of the entire foveal depression is $5^{\circ}$, and that of the combined fovealparafoveal area is approximately $8^{\circ}$. Topographic relationships are maintained throughout the visual pathway such that the cortical representation of the fovea lies along the posterior portions of the lips of the calcarine fissure, the parafovea and retinal periphery being interconnected with intermediate and anterior portions, respectively.

The cortical topography suggests that visually evoked activity detectable at the scalp may be restricted largely to the foveal component. This notion is supported by physiological studies that have shown the occipital response to a point source of light to be largest when the stimulus falls within the foveal region of the retina (Copenhaver and Perry 1964; Van Balen et al. 1966; Eason et al. 1967; Ohba 1967; DeVoe et al. 1968). An approach utilizing various luminous rings and discs similarly has pointed to the foveal contribution as the predominant one (Rietveld et al. 1965).

Seemingly at variance with the foregoing considerations are data obtained with relatively wide-angle or diffuse stimulation which indicate the field characteristics of the visual-evoked

\footnotetext{
${ }^{1}$ Presented in part at the Twenty-fifth Annual Meeting of The American Electroencephalographic Society, Sept. 16-18, 1971.
}

response may be inconsistent with those predicated upon excitation of the foveal zone of the visual cortex, regions well outside the occipital area being active. That this holds true for the early, as well as the late, components (Kooi and Bagchi 1964; Gastaut and Regis 1965; Rémond and Lesèvre 1965; Morocutti et al. 1966; Creutzfeldt and Kuhnt 1967; Goff et al. 1969) underscores the divergence of the two sets of data, since the early portion has often been designated "primary" or "specific" activity and connected with direct projections to the visual cortex. Creutzfeldt and Kuhnt (1967), on the contrary, believe the early negative potential, because of comparatively long latency and wide distribution, to correspond to the "nonspecific potential of Buser et al. (1959)".

This communication presents the results of two series of experiments, designed to investigate the problem outlined above, in which the spatial distribution of the early negative potential has been examined in relation to (1) a graduated series of flashing circular targets subtending visual angles from $1^{\circ}$ to $32^{\circ}$, and (2) a graduated series of central opacities subtending visual angles from $1^{\circ}$ to $16^{\circ}$ situated within a flashing circular target having a fixed outer visual angle of $32^{\circ}$.

The term "visual-evoked response (VER)" has been used above and will be used subsequently in the widest sense to refer to all cerebral activity, or any portion of the activity, elicited by repeated single visual stimuli and extracted from extraneous signals by the averaging technique. The term "early negative potential" is 
applied to distinguish the initial surface-negative portion of the VER, culminating between 40 and $80 \mathrm{msec}$, from its other components.

\section{METHODS}

Four male staff members, all experienced research subjects, participated in the experiments.

Eight-channel response averaging was carried out on line with a Grass Model 6 electroencephalograph and two CAT 400 Signal Averagers. All eight EEG channels were monitored continuously, a ninth channel being used for the stimulus marker. Amplifier band widths $(3 \mathrm{~dB})$ were $1-90 \mathrm{c} / \mathrm{sec}$. The system was calibrated by obtaining comparable averages of a $5 \mu \mathrm{V}$ squarewave signal. The averages were written out on paper and Mylar transparencies with a HewlettPackard X-Y point plotter. Line voltage supplies to the photic stimulator and function generator (ENSCO) were stabilized by a Sola voltage regulator.

Ordinary silver-cup electrodes were placed in two basic arrangements of 10-20 System lead positions: (1) an anterior-posterior midline array including the $\mathrm{F}_{\mathrm{pz}}, \mathrm{F}_{\mathrm{z}}, \mathrm{C}_{\mathrm{z}}, \mathrm{P}_{\mathrm{z}}$ and $\mathrm{O}_{\mathrm{z}}$ placements plus a left infraorbital and midline suboccipital $\left(\mathrm{SO}_{\mathrm{z}}\right)$ electrode, and (2) posterior transverse arrays including the $\mathrm{T}_{5}, \mathrm{O}_{1}, \mathrm{O}_{2}, \mathrm{O}_{2}$ and $\mathrm{T}_{6}$ placements, along with $\mathrm{P}_{3}, \mathrm{P}_{z}$ and $\mathrm{P}_{4}$. The midline suboccipital electrode $\left(\mathrm{SO}_{\mathrm{z}}\right)$ was placed $10 \%$ of the nasion-occiput distance below the occiput. All scalp leads were paired with a noncephalic reference. The arrangement of Stephenson and Gibbs (1951) proved as suitable as any of more than a dozen that were tried with the proviso that the sternal lead not be placed immediately over the region of insertion of the sternocleidomastoid muscle.

Except for a small, dark fixation point which subtended a visual angle of approximately $5^{\prime}$ at the standard viewing distance of $45.8 \mathrm{~cm}$, the subject, sitting upright in a comfortable easy chair, viewed an all white visual field consisting of three areas, the central target area (Fig. 1,a), an outer, circular zone (Fig. $1, b$ ) and a peripheral area (Fig. 1,c). The central target area was illuminated from behind by two light sources, the flash unit of a Grass Model 2 photostimulator and four 6-watt tungsten lamps (Fig. 1,g). The

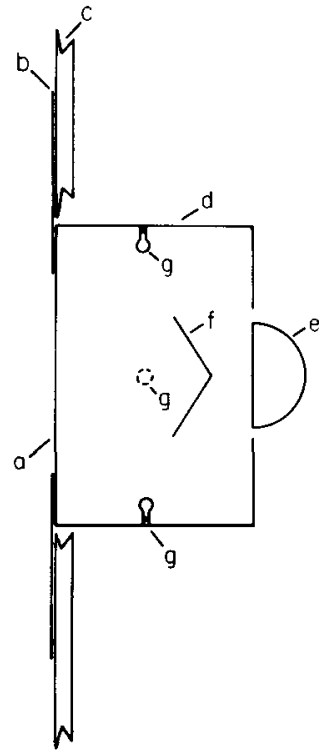

Fig. 1. Diagram of light source drawn to scale. $a$ : Exchangeable white circular card with central aperture. $b$ : White, hemicylindrical floor-to-ceiling drapery $(56 \mathrm{~cm}$ radius) and chair cloth. $c$ : Opal glass. $d$ : Drum-shaped enclosure with white interior. $e$ : Flash lamp with opal glass face. $f:$ Metal cone reflector. $g$ : Four interior, 6-watt, battery-powered, tungsten light bulbs.

former provided the stimulus, the latter, an adjustable background level of light for the central area. Areal variations of luminance were less than $\pm 5 \%$ for the two sources. The circular, white cardboard surface subtended a visual angle of $90^{\circ}$. Together with the white cloth surface which occupied the entirety of the remaining peripheral visual field, the cardboard surface was directly illuminated by a rheostatically controlled ceiling fixture situated above and behind the subject. Selective shading of the fixture gave an even distribution of light over the field of view $( \pm 10 \%)$. A series of interchangeable cards having circular apertures subtending visual angles of $32^{\circ}, 16^{\circ}, 8^{\circ}, 4^{\circ}, 2^{\circ}$ and $1^{\circ}$ was available. Opaque circles subtending comparable visual angles were used in conjunction with large-aperture cards to give annular patterns.

Peak stimulus luminance at the opal glass face of the light source was determined to be $63 \times$ $10^{3}$ mlam with a Gamma Scientific Telephotometer, Model 2000. In order to minimize the effects of entoptic light scatter without extinguishing the cortical response to the stimulus, the field luminance was set at a photopic level of 8 mlam. 
When pupil size and spectral characteristics of the light sources are taken into consideration, a level of this intensity may be expected to produce essential saturation of the rod mechanisms (Aguilar and Stiles 1954). In preliminary experiments with $2^{\circ}$ targets having the same peak luminance as that used in the final runs, a field luminance of 6 mlam was sufficient to suppress the VER when the target was focused on the blind spot. Field luminance measurements were taken before and after each experimental run.

A chin rest assisted the subjects in achieving maximal relaxation of posterior cervical muscles and fixed the position of the head. The subjects were instructed to blink between stimuli, once every $8-10$ stimuli. The subjects' pupils were dilated with $0.5 \%$ cyclopentolate hydrochloride.

The flashes were presented in an irregular manner at intervals of $0.8-1.2 \mathrm{sec}$. A delay of 10 msec was introduced between initiation of the averaging cycle and presentation of the flash with a Grass S88 physiological stimulator. Six hundred trials constituted one run. A second identical run was obtained routinely to assess repeatability of the data.

The amplitude measurements upon which the spatial graphs are based were obtained in the following way for the full-circle series. The peak of the midoccipital early negative response to the largest target size $\left(32^{\circ}\right)$ was located, and its latency from the moment of the stimulus determined. Comparable deflections were then identified within the responses to successively smaller targets. For the larger targets, these points corresponded to the peak of the early negative response. With smaller targets, in the few instances in which the form of the response was slightly altered, the deflection corresponding most closely to the previously established latency trend was selected. These latency values will be found under Results. In the central opacity series, the peak of the early negative potential for the $32^{\circ}$ target was used as the point in time at which all amplitude measurements were made. The amplitude was then measured from the average voltage level over the $5 \mathrm{msec}$ period immediately preceding the stimulus to the voltage level at the same latency for each area under each stimulus condition, the values so obtained being used to construct instantaneous, spatial voltage contours. Variations in amplitude measurements of comparable data points between successive technically satisfactory runs are also shown in the graphs presented under Results. Additional sources of variance involving differences in sampling of field voltages, the subject's degree of attentiveness and physical characteristics of the set-up, which could not be entirely circumvented, resulted in slightly larger variations in data collected during separate sessions.
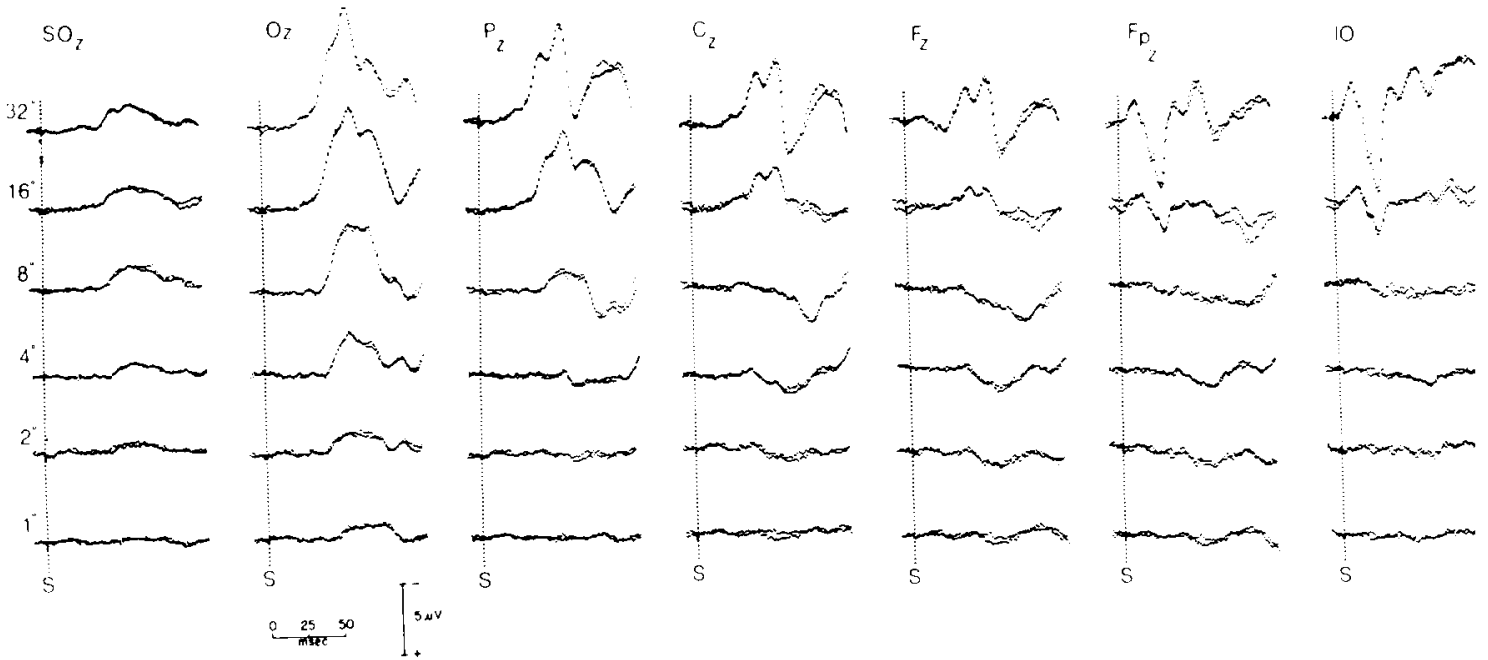

Fig. 2. Alterations of average longitudinal field pattern of occipital early negative potential as target size is systematically varied are depicted for normal subject. Curves represent superpositions of two averages of 600 responses in this and subsequent figures. See text for further description. 
RESULTS

Step-wise variation of target size from $1^{\circ}$ to $32^{\circ}$ brought about a systematic series of changes

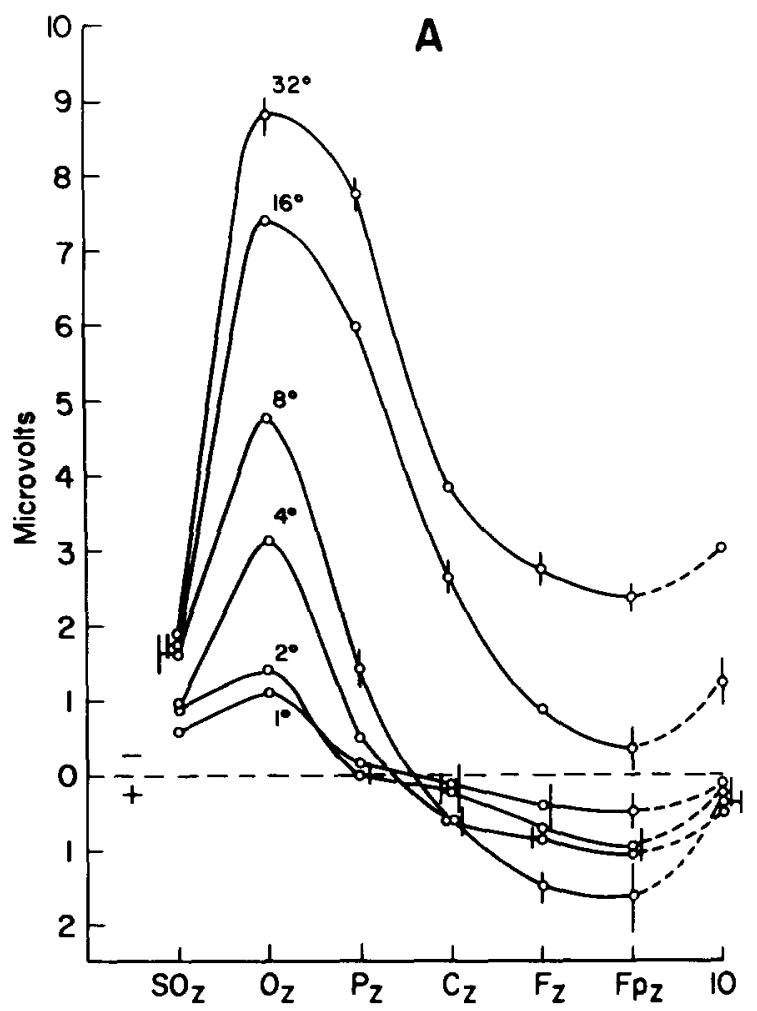

of the early negative potential with respect to amplitude and distribution (Fig. 2;3, $A ; 4, A$; $5, A$ and $6, A$ ). Latencies to the peak of the wave varied only slightly in relation to target size

Fig. 3. Average (n1200) instantaneous midline voltage gradients of early negative potential in subject with large response are graphed in relation to target size $(A)$ and in relation to size of central opaque circle within larger target $(B)$. Refer to Table I for latencies of early negative potential in $A$. Measurements for $B$ were made at fixed latency of $64 \mathrm{msec}$ (see Methods). In this and subsequent graphs, bars represent difference between measurements for successive n 600 runs. Absence of bar indicates difference of $0.2 \mu \mathrm{V}$ or less.
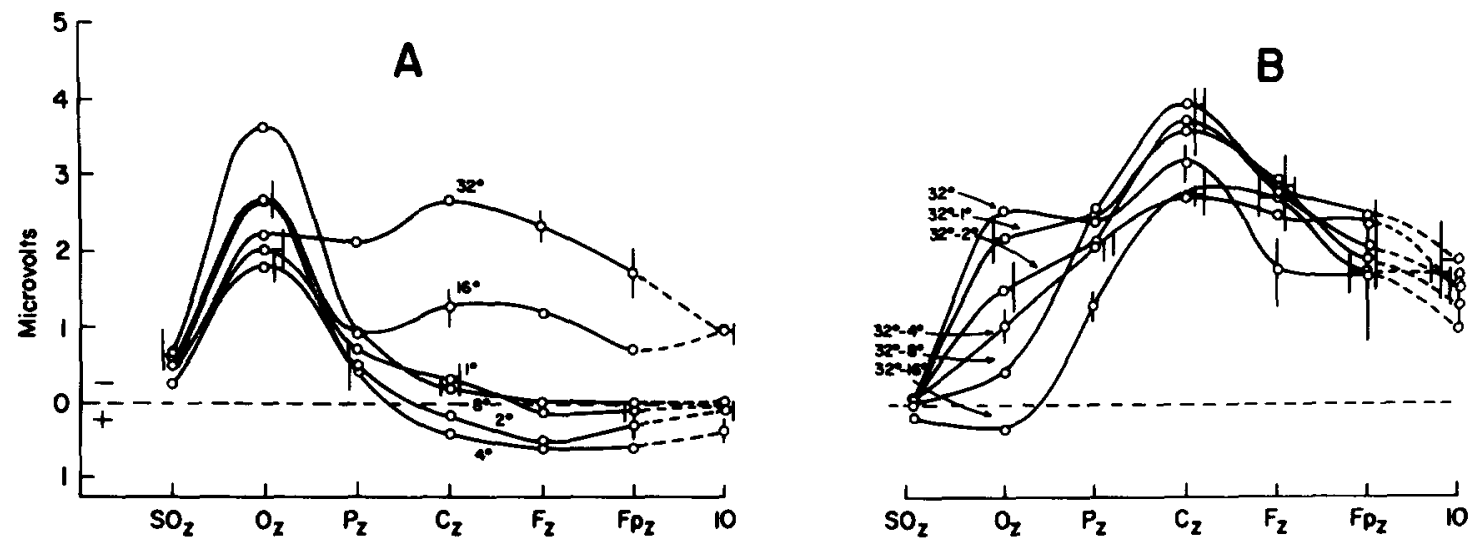

Fig. 4. The same types of data as those illustrated in Fig. 3 are plotted for second subject. Latencies of early negative potential will be found in Table I. Measurements for $B$ were made at fixed latency of $55 \mathrm{msec}$. 
(Table I). The salient features of the longitudinal voltage fields elicited by small and large targets are illustrated by the experimental results in the initial subject (Fig. 2 and $3, A$ ). The exceptionally large responses of this subject permitted clear differentiation of the field pattern at each target size. It may be observed that targets of $1^{\circ}$ to $8^{\circ}$ gave rise to dipolar voltage fields, enlargement

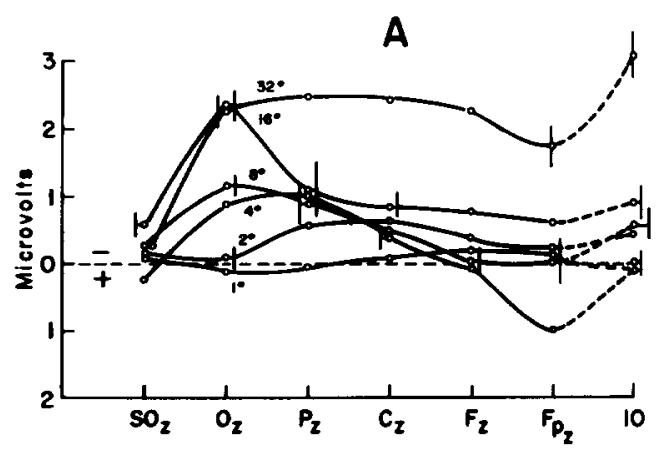

of stimulus area being associated with an increasing negative potential posteriorly and a similarly increasing potential but of opposite polarity anteriorly. With further increases in target size $\left(16^{\circ}\right.$ and $\left.32^{\circ}\right)$, the posterior negativity continued to grow larger whereas, anteriorly, the direction of change reversed, the entire longitudinal field becoming surface-negative.

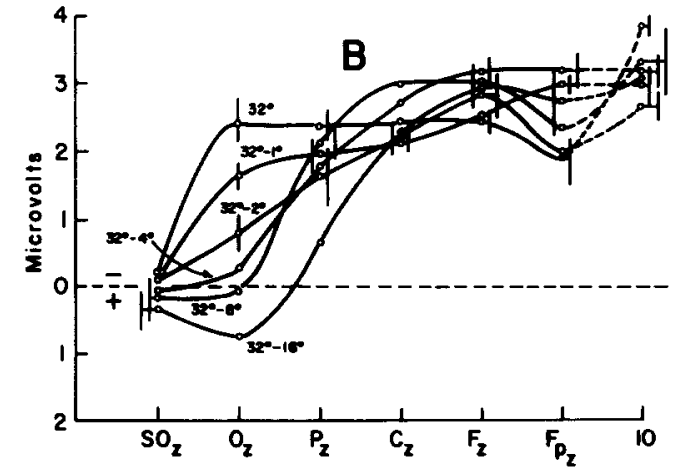

Fig. 5. Comparable data to those in Fig. 3 are plotted for third subject. Latencies of early negative potential for $A$ are given in Table I. Measurements for $B$ were made at fixed latency of $65 \mathrm{msec}$.
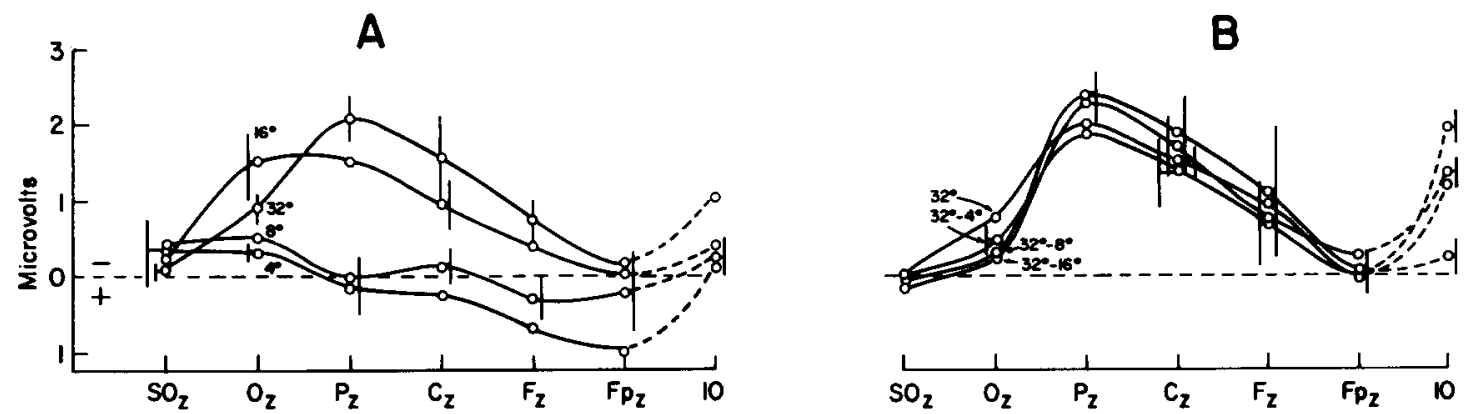

Fig. 6. This subject had extremely small responses, $1^{\circ}$ and $2^{\circ}$ targets giving no definable responses. Otherwise the data are comparable to those of other subjects shown in Fig. 3-5. Latencies of early negative potential for $A$ are given in Table I. Measurements for $B$ were made at fixed latency of $49 \mathrm{msec}$.

TABLE I

Latencies (msec) to peak of early negative potential at $\mathrm{O}_{z}$.

\begin{tabular}{|c|c|c|c|c|c|c|c|c|c|c|c|c|}
\hline \multirow[b]{2}{*}{ Stimulus size } & \multicolumn{3}{|c|}{ Subject 1} & \multicolumn{3}{|c|}{ Subject 2} & \multicolumn{3}{|c|}{ Subject 3} & \multicolumn{3}{|c|}{ Subject 4} \\
\hline & Run 1 & Run 2 & Av. & Run 1 & Run 2 & $\mathrm{Av}$ & Run 1 & Run 2 & Av. & Run 1 & Run 2 & Av. \\
\hline $32^{\circ}$ & 63 & 63 & 63 & 56 & 55 & 56 & 65 & 66 & 66 & 48 & 49 & 49 \\
\hline $16^{\circ}$ & 63 & 63 & 63 & 56 & 56 & 56 & 65 & 65 & 65 & 51 & 51 & 51 \\
\hline $8^{\circ}$ & 63 & 61 & 62 & 58 & 59 & 59 & 68 & 68 & 68 & 51 & 51 & 51 \\
\hline $4^{\circ}$ & 63 & 63 & 63 & 60 & 60 & 60 & 69 & 68 & 69 & 52 & 52 & 52 \\
\hline $2^{\circ}$ & $(70)$ & 64 & 67 & 61 & 59 & 60 & 68 & 68 & 68 & - & - & - \\
\hline $1^{\circ}$ & (60) & 65 & 63 & 65 & 64 & 65 & 66 & 69 & 68 & - & - & $\ldots$ \\
\hline
\end{tabular}

( ): Comparable wave although not peak (see Method). 


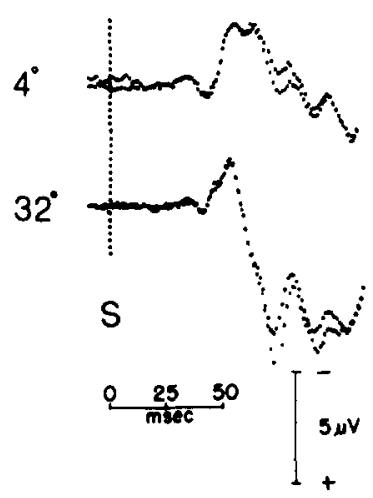

Fig. 7. Comparison of occipital response to $4^{\circ}$ and $32^{\circ}$ targets in subject with attenuation of surface-negative response to larger target. Graphic data of subject shown in Fig. 4.

Other subjects showed similar sequences with but minor variations (Fig. $4, A ; 5, A$ and $6, A$ ). The variations of greatest interest are those involving the relative amplitudes of the negative potential at occipital and preoccipital locations. It can be seen that enlargement of stimulus area beyond a certain point may not be accompanied by an additional increment of response posteriorly, and that small decrements are actually possible (Fig. 4, $A ; 6, A$ and 7). This circumstance, occurring along with continuing development of the anterior negativity, may result in equalization or reversal of occipitalpreoccipital amplitude relationships.

Consideration of the wave forms and field patterns of the negative activity and of the electroretinogram throughout the data series (Fig. 2) make it clear that volume conduction of electroretinal activity played no significant role in the evolution of the voltage fields under observation. It may be noted, for example, that (1) the growth of the early negativity proceeded from posterior to more anterior regions, and (2) the $32^{\circ}$ and $16^{\circ}$ measurements at the $F_{z}$ location were consistently larger than those at the $F_{p z}$ site where the electroretinal contribution would be expected to be the greatest (Fig. $2 ; 3, A ; 4, A$; $5, A$ and $6, A$ ).

The series of annular targets generated quite different sets of longitudinal voltage fields (Fig. $3, B ; 4, B ; 5, B ; 6, B$ and 8 ). These fields were characterized by a decreasing negativity in the occipital region relative to an increasing central opacity, the anterior negativity remaining well developed even when elicited by the outermost ring $\left(32^{\circ}-16^{\circ}\right)$. Corresponding decreases of lesser degree in the parietal area evident in Fig. $4, B$ were not a constant finding in the other subjects.

The transverse field characteristics were also studied. These were marked by a gradually decreasing voltage bilaterally from a midline maximum, voltage becoming exceedingly small far laterally, regardless of the areal pattern of

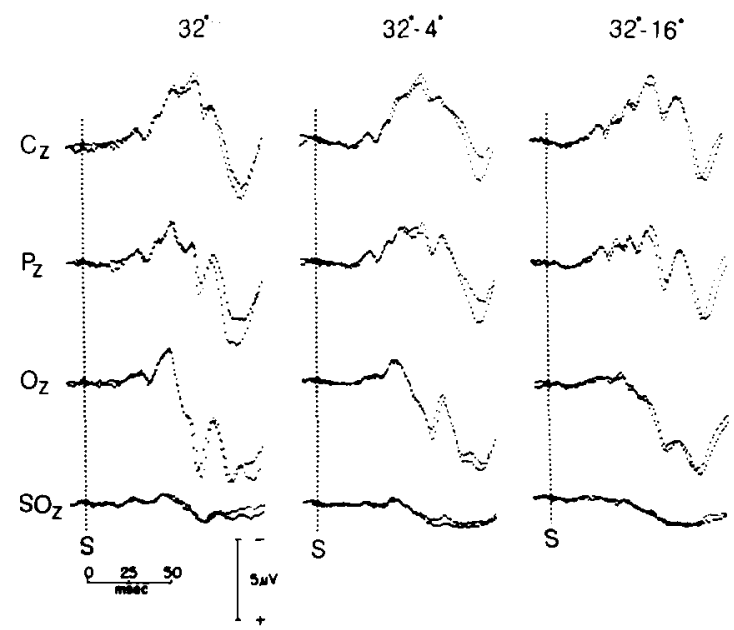

Fig. 8. Sets of average responses illustrate the differential effects upon amplitude in occipital region as compared with anterior sites with $4^{\circ}$ and $16^{\circ}$ central opacities. Samples are from same set of data upon which graph $4, B$ is based.

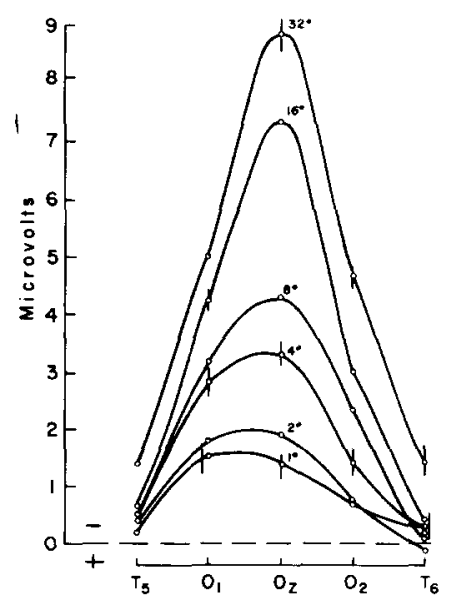

Fig. 9. The transverse voltage gradients of the early negativity relative to stimulus size are shown for normal subject. Note lesser asymmetry of field pattern with large targets compared with small targets. 
the stimulus. No consistent differences between the field gradients obtained under the two series of stimulus conditions could be recognized. The posterior transverse fields of one subject are shown in Fig. 9.

Because light intensity has been held constant, total light flux has varied in parallel with stim-

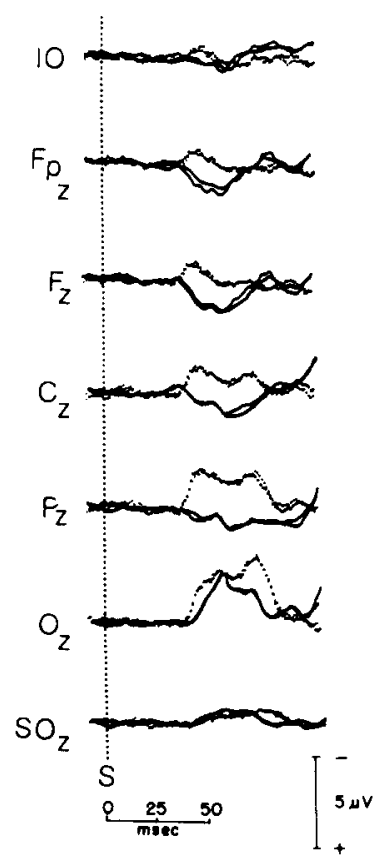

Fig. 10. The effect upon the average longitudinal field pattern of the early negative potential caused by changing stimulus area while holding light flux constant is illustrated. The dotted lines represent 2 runs obtained with a $32^{\circ}$ target having a luminance of $984 \mathrm{mlam}$, the continuous lines, similar runs taken with a $4^{\circ}$ target having a luminance of 63,000 mlam. A neutral density filter of $1.8 \mathrm{log}$ units was introduced at the lamp face to achieve the reduction in intensity. See text for further description.

ulus area in the experiments described above. Consequently, it is pertinent to inquire about the effect of increased target size with light intensity reduced to give equivalent total light fluxes. In order to maximize possible field differences, stimuli of substantially different sizes were chosen, $4^{\circ}$ and $32^{\circ}$, the areal proportionality of 64 being adjusted for by reducing light intensity by a factor of $1 / 64$ th. The results of the experiment (Fig. 10) showed two points of major interest. Firstly, although the amount of light falling on the central $4^{\circ}$ of the retina was greatly reduced with the low. luminance $32^{\circ}$ target, the magnitude of the occipital response was very similar to that obtained with the more intense $4^{\circ}$ target. Secondly, the presence of the preoccipital early negativity again proved to be a function of large target size. It is to be further noted that no electroretinogram was visible in either case, ruling out volume-conducted activity from the retina as a cause of the field differences.

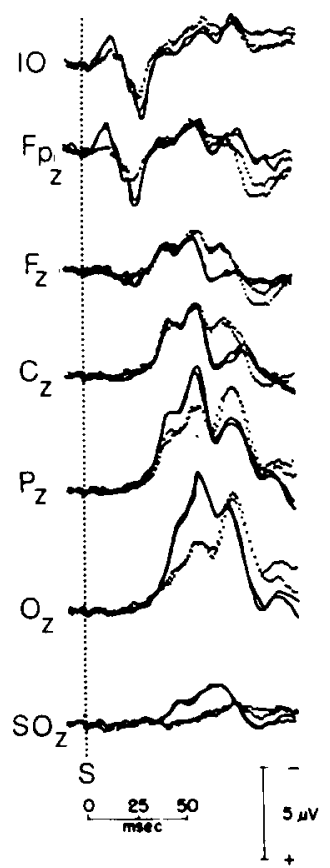

Fig. 11. The average longitudinal field patterns of the early negative potential when elicited by an annular target, $22.6^{\circ}$ to $32^{\circ}$ in width (dotted lines), and a circular target, $22.6^{\circ}$ in diameter (continuous lines), are shown. See text for further description.

Examination of the field distributions of the early negative potential obtained with a $22.6^{\circ}$ circle and a $22.6^{\circ}-32^{\circ}$ ring, stimulus patterns also having the same total light fluxes since their areas are equal, confirmed the areal relationships previously demonstrated (Fig. 11). Compared to those elicited by the circular target, the peripheral ring gave similar responses at central and frontal recording sites, whereas posteriorly, the central portion of the complex so elicited was substantially smaller, more so in the occipital than parietal region. 


\section{DISCUSSION}

The principal results of the present investigation are as follows: (1) the existence of two types of longitudinal voltage gradients of the early negative potential has been confirmed; (2) the stimulus conditions under which each type can be elicited have been delineated; and (3) the serial modifications by which one type is transformed into the other have been elucidated.

It appears that the site of retinal stimulationwhether predominantly foveal or peripheral or a combination of the two-is a significant factor underlying the field characteristics of the early negative potential. Afferent retinal impulses arising predominantly from the fovea give rise to a local occipital negativity associated with a surface-positive potential variation in more anterior regions. As target size is increased, the more striking changes occur in the activity recorded from preoccipital sites, being marked by a reversal of polarity and the development of a widespread major surface-negative wave within the same time domain as the occipital negativity. The less striking occipital changes variously include a further increase in the amplitude of the negative wave or an actual slight decrease. By reducing the amount of light falling on foveal and near-foveal regions while at the same time keeping peripheral retinal stimulation constant, it can be demonstrated that the anterior negativity is largely the result of afferent impulses originating in extraparafoveal regions of the retina, since the decrease in voltage which is produced in this way is almost wholly restricted to the occipital region. The parafoveal area has an intermediate position with respect to these relationships. Viewed as a summation of complex and widespread cerebral voltage sources excited by an aggregate retinal volley, the early negative potential thus appears to reflect, at any given cortical locus, the resultant of the combined input from various retinal areas. The prediction of Vaughan (1969) — based upon consideration of the orientation and location of possible voltage sources about the calcarine fissurethat peripheral retina should contribute little to the VER is not borne out by these data.

Stimulation of the retina outside of the area of the image by stray light may be expected to have a general quantitative effect on the absolute voltages of cerebral responses whenever retinal excitation is achieved through light contrast. Because of this factor, even though the background light level was sufficiently high to suppress largely rod mechanisms, it is important to direct attention to the fact that the qualitative results would not be altered by this variable since its effect is spatially similar to that of the experimental variable. In the full-disc series, the decreasing stray light, as target size is decreased, would result in decreasing peripheral retinal stimulation as does the areal effect of changing target size. In the annulus series, the decreasing stray light, as target size is decreased, would result in decreasing foveal stimulation, also in parallel with the areal effect. In the latter case, the theoretical possibility exists that some change in stray-light stimulation of the retinal periphery beyond the outer border of the annulus could also be occurring. However, the cerebral field gradients showed no evidence of a significant effect. Moreover, it was established that experimental manipulation of either stimulus size or stimulus location, with total light flux held constant, was sufficient to effect the same type of alteration of the longitudinal distribution of the early negative potential as observed in the main series of experiments.

There have been previous studies suggesting, on morphologic or temporal grounds, that the contribution to the VER from excitation of the fovea might be distinguishable from an extrafoveal component. Van Balen et al. (1966) identified a surface-positive deflection with a latency of $100 \mathrm{msec}$ with foveal activity and one with a latency of $140 \mathrm{msec}$ with extrafoveal activity. Ohba (1967) and Bourne et al. (1971) have observed that late components of VERs elicited by extrafoveal stimulation had longer latencies than those from foveal stimulation. Rietveld et al. (1965) noted differences in the alterations of component waves of the VER associated with differential stimulation of foveal and parafoveal regions.

Our results in respect to the changing magnitude of the occipital response in relation to target size are entirely concordant with those of other investigations. Tepas and Armington (1962) found the overall amplitude of the occipital 
response to $5 / \mathrm{sec}$ stimulation to increase over a target range of $24^{\prime}$ to $8^{\circ}$ with no further increase, or a decrease, to a $15^{\circ}$ target, depending upon stimulus luminance. Rietveld et al. (1965) evaluated the occipitocortical response in darkadapted subjects to luminous discs subtending visual angles of $28^{\prime}$ to $7^{\circ} 38^{\prime}$. Illustrated changes include a gradual increase in the magnitude of the rapid components of the early negative potential over the range studied. The subjects we examined also had progressive increases up to the $8^{\circ}$ target size with maximal amplitudes being reached variously at $8^{\circ}, 16^{\circ}$ and $32^{\circ}$.

From the physiological standpoint, the finding that the distribution of the early negative potential is dependent upon the spatial nature of the retinal input emphasizes the fundamental importance of topographic aspects of retinocerebral organization. At the same time, there is a problem posed as to the central pathways mediating the activity since it appears to have spatial properties consistent with either specific or non-specific systems under different stimulus conditions. The problem is compounded by the fact that anterior and posterior components occur in the same time domain. Anatomical and animal physiological data are also inconclusive. The well known connections between area 17, 18 and 19 , along with the major fiber bundlesthe association bundles, the superior longitudinal fasciculus and the inferior occipitofrontal fasciculus - make tenable the possibility that the response reflects activity within the specific and functionally related corticocortical systems. Lending strong physiological support to this notion are the findings in the monkey (Saimiri sciureus) of (1) a separable, visually evoked prestriate response, dependent upon an intact pathway from striate cortex (Cowey 1964), and (2) frontal responses to electrical stimulation of cortex in the vicinity of the primary visual area that persist following thalamectomy (Bignall and Imbert 1969). There are other data, however, indicating the presence of direct pathways from thalamic nuclei to extrastriate cortex. These may pass through non-specific or association thalamic nuclei or both. It has recently been established further in one species (Felis domesticus) that neither non-specific or association nuclei, as usually defined, may be re- quired for elaboration of association responses, the essential thalamic structure being rather lower, layer B of the dorsolateral geniculate body (Narikashvili et al. 1969). Thus the question of the nature of the central mechanism underlying the preferential relationship between the fovea and the cortical region of termination of the visual pathway on the one hand and retinal periphery and more anterior regions on the other remains an open one.

Some clinical inferences may be drawn from the results of the study since the two experimental conditions may be viewed as models of two common types of field defects-the decreasing circular target simulating general constriction of the peripheral visual field, the increasing central opacity simulating an enlarging central scotoma. In both instances, it is apparent that the amplitudes of the early negative potential at any given recording site may correlate poorly with spatial variations in retinal input. It is possible to recognize, however, the presence of decreased peripheral or decreased central retinal input from inspection of the longitudinal voltage fields in individual subjects with known types of VER configurations. The inter-individual variability of the field patterns makes it improbable that the phenomena described will have direct diagnostic utility, but they may explain some differences in results in patients being studied for central lesions of the visual pathway where the situation is complicated by involvement of the optic nerve or of the eye itself.

\section{SUMMARY}

Variations in topographic characteristics of the early negative potential of the human, flash-evoked cerebral response were related to (1) a graduated series of stimulus sizes subtending visual angles from $1^{\circ}$ to $32^{\circ}$, and (2) a graduated series of central opacities subtending visual angles from $1^{\circ}$ to $16^{\circ}$ placed within a $32^{\circ}$ stimulus.

The longitudinal field pattern of the early negative potential was shown to be a function of the spatial characteristics of the visual stimulus. Foveal stimulation produced a local, early negative potential in the occipital region, generally associated with surface-positive ac- 
tivity anteriorly, whereas peripheral stimulation gave a widespread early negative potential, relatively less prominent in the occipital region than in preoccipital areas. Intermediate field-gradient configurations resulted from various combinations of foveal, parafoveal and peripheral stimulation.

The effect of addition of extrafoveal to foveal stimulation upon the magnitude of the occipital early negative potential proved to be subjectdependent.

\section{RESUME}

INFLUENCES FOVEALES ET EXTRAFOVEALES SUR LA TOPOGRAPHIE DU POTENTIEL EVOQUE VISUEL NEGATIF PRECOCE CHEZ L'HOMME

Les variations des caractéristiques topographiques du potentiel négatif précoce de la réponse cérébrale évoquée par la lumière ont été reliées à (1) Une série de stimuli de dimension progressivement croissante, sous-tendant des angles visuels de $1^{\circ}$ à $32^{\circ}$, et (2) une série progressive d'opacités centrales sous-tendant des angles visuels de $1^{\circ}$ à $16^{\circ}$, placés à l'intérieur d'un stimulus de $32^{\circ}$.

Le pattern de champ longitudinal du potentiel négatif précoce se présente comme une fonction des caractéristiques spatiales du stimulus visuel. La stimulation fovéale provoque un potentiel négatif précoce local au niveau de la région occipitale, associé généralement à une activité surface-négative antérieure, tandis que la stimulation périphérique donne un potentiel négatif précoce très étendu, relativement moins dominant dans la région occipitale que dans les régions pré-occipitales. Des configurations de champ de gradient intermédiaires résultent de diverses combinaisons de stimulation fovéale, para-fovéale et périphérique.

Les effets de l'addition de la stimulation extrafovéale à la stimulation fovéale sur la grandeur du potentiel négatif précoce occipital dépendent du sujet.

\section{REFERENCES}

Aguilar, M. and Stiles, W. S. Saturation of the rod mechanism of the retina at high levels of stimulation. Optica Acta (Lond.), 1954, 1:59-65.
Bignall, K. E. and Imrert, M. Polysensory and corticocortical projections to frontal lobe of squirrel and rhesus monkey. Electroenceph. clin. Neurophysiol., 1969, 26: 206-215.

Bourne, J. R., Childers, D. G. and Perry Jr., N. W. Topological characteristics of the visual evoked response in man. Electroenceph. clin. Neurophysiol., 1971, 30: 423.436.

Buser, P., Borenstein, P. et Bruner, J. Etude des systèmes "associatifs" visuels et auditifs chez le chat anesthésié au chloralose. Electroenceph. clin. Neurophisiol.. 1959, II: 305-324.

Copenhaver, R. M. and Perry $J_{R}$., N. W. Factors affecting visually evoked cortical potentials such as impaired vision of varying etiology. Invest. Ophthal, 1964, 3: 665-675.

CowEy, A. Projection of the retina on to striate and prestriate cortex in the squirrel monkey. Saimiri sciureus. J. Neurophysiol., 1964, 27: 366-393.

Creutzfeldt, O. D. and Kunnt, U. The visual evoked potential: Physiological, developmental and clinical aspects. Electroenceph. clin. Neurophysiol., 1967, Suppl. 26: $29-41$.

Devof, R., Ripps, H. and Vaughan JR., H. Cortical responses to stimulation of the human fovea. Vision Res., 1968 , 8: $135-147$.

EASON, R. G., Oden, D. and White, C. T. Visual evoked cortical potentials and reaction time in relation to site of retinal stimulation. Electroenceph. clin. Neurophysiol., 1967, 22: 313-324.

Gastaut, H. and Regis, $H$. The visually evoked potentials recorded transcranially in man. In L. D. PROCTOR and W. R. ADEY (Eds.), NASA svmposium on the analysis of central nervous system and cardiovascular data using computer methods. NASA, SP-72, Washington, D.C., 1965: 7-34

Goff. W. R., Matsumiya, Y., Allison, T. and Goff, G. D. Cross modality comparisons of averaged evoked potentials. In E. DonchIN and D. B. Lindsley (Eds.), Average eloked potentials. Methods, results, and evaluations. NASA, Washington, D.C., 1969: 95-118.

KooI, K. A. and BAGCHI, B. K. Visual evoked responses in man. Normative data. In R. KatzMAN (Ed.). Sensory evoked responses in man. Ann. N.Y. Acad. Sci., 1964, 112: 254-269.

Morocutti, C., Sommer-Smith, J. A. und Creutzfeldt, O. Das visuelle Reaktiomspotential bei normalen Versuchspersonen und charakteristische Veränderungen bei Epileptikern. Arch. Psychiat. Nertenkr., 1966, 208: 234-254.

Narikashvili, S. P., KajaIA, D. V. and TimChenKo, A. S. On the origin of cortical association responses to visual stimulation in the cat. Brain Res., 1969, 14: 417-425.

OнBA, N. Visual evoked responses in man by localized retinal stimulation. Jap. J. Ophthal, 1967, 2: 221-226.

Polyak, S. L. The retina. University of Chicago Press, Chicago. Ill., 1941.

REMOND, A. et LesÈv're, N. Distribution topographique des potentiel évoqués visuels occipitaux chez l'homme normal. Rev neurol., 1965, 1/2: 317-330.

Rietveld, W. J., Tordoir, W. E. M. and DuyfF, J. W. Contribution of fovea and parafovea to the visual evoked 
response. Acta phrsiol. pharmacol. neerl., 1965, 13: $330-339$.

Stephenson, W. A. and Griss, F. A. A balanced noncephalic reference electrode. Electroenceph. clin. Neurophysiol., 1951, 3: 237-249.

Tepas, D. I. and Armington, J. C. Properties of evoked visual potentials. Vision Res., 1962, 2: 449461.

Van Balen. A. Th. M., Denier van der Gon, J. J. and HellendoORN, E. H. The differentiation between respon- ses of foveal and extrafoveal stimuli in the ERG and FEG. In H. M. Burian and J. H. JaCOBSON (Fds.). Clinical electroretinography. Vision Res., Suppl.. 1966: 255-262.

VAUGHAN JR., H. G. The relationship of brain activity to scalp recordings of event-related potentials. In $\mathrm{E}$. DONichin and D. B. LINDSLEY (Eds.), Average evoked potentials. Methods, results, and evaluations. NASA. Washington, D.C. 1969: 45-75. 